\title{
A Novel HPLC Method Validation Based on Analytical Techniques of Metoclopramide Benzamide Derivative (Metoclopramide Base) and its Determination from Solid Dispersion by Solvent Evaporation Method
}

\author{
Nancy Kahali*, Jasmina Khanam \\ Department of Pharmaceutical Technology, Jadavpur University, Kolkata, India.
}

\author{
ARTICLE INFO \\ Article history: \\ Received on: 28/10/2017 \\ Accepted on: 20/01/2018 \\ Available online: 27/02/2018

\section{Key words:} \\ HPLC, metoclopramide \\ base, extraction, solid dis- \\ persion, validation.
}

\begin{abstract}
The crucial endeavor in this method is focused on the study analysing recovery and column efficiency (theoretical plate) after extraction of metoclopramide from PVP K30-Metoclopramide (3:1 w/w) solid dispersion (SD). The proposed work also presents a reversed-phase high performance liquid chromatography method for the detection of very small amount of metoclopramide base followed by different analytical techniques. In this context, it may be noted that the values of limit of detection (LOD) and limit of quantitation (LOQ) for the metoclopramide base as obtained are, $0.052 \mu \mathrm{g} / \mathrm{mL}$ and $0.159 \mu \mathrm{g} / \mathrm{mL}$ respectively. The linearity is performed in the range of 2-20 $\mu \mathrm{g} /$ $m L$; performance of column remained satisfactory throughout the analysis, $N=4927-2434$. The percentage recovery of pure and extracted metoclopramide ranges from $103-105 \%$ and $86-120 \%$ approximately. The results collectively demonstrate that the proposed method is selective. Clear isolation of metoclopramide from SD is achieved without any solid state interference.
\end{abstract}

\section{INTRODUCTION}

Metoclopramide belongs to the group of dopamine receptor antagonists and it is used mainly as an antiemetic agent (Ritter et al., 2008). It is applied in the treatment of symptomatic gastro-oesophageal reflux, chemotherapy-inducednausea and vomiting, small bowel intubation radiological examination, and even in migraine (Radwan, 1998). It prevents gastric smooth muscle relaxation caused by dopamine release and thus enhances cholinergic response of gastrointestinal tract (Deokate and Gorde, 2014). Metoclopramide. Figure 1 is chemically known as 4-amino-5-chloro-N-[2-(diethylamino) ethyl]-o-anisamide (Shakeel et al., 2014). Various tablets containing oral dose of 10,15 or $30 \mathrm{mg}$ of active substance available in the market in its hydrochloride form are used to overcome its solubility problem. Lower dose is prescribed for patients with renal problem.

\section{"Corresponding Author}

Nancy Kahali, Jadavpur University, 188, Raja S. C. Mallick Road, Kolkata-700032, India.E-mail: kahalinancy@gmail.com
Transdermal delivery of antiemetic drugs (base form) with low dose is very much effective to the chemotherapy patients. Hence, a reliable sensitive and easy analytical method must be built up to detect the analyte and primarily to facilitate its detection in in-vitro/in-vivo studies.

Polyvinylpyrrolidone (PVP) is a multifaceted polymer with instinctive surface activity. It possesses large molecular mass with hydrophilic and hydrophobic parts. PVP comprises polar amide group in combination with non-polar methylene $\left(-\mathrm{CH}_{2}\right)$ and methane $(-\mathrm{CH})$ groups. The molecule is soluble in a number of organic solvents except ketones and ethers and exists as a loose random loop in solution. PVP leads to its initial medical usage as a plasma substitute and, as such, it is physiologically inactive. Of late this has been discarded because it accumulates a large molecular weight fraction in the body. It is essentially used in pharmaceutical background as a controlled release substance, binder and transdermal permeation enhancer (Jones et al., 2004).

Various pharmaceutical strategies have now been applied to overcome poor dissolution rate of metoclopramide viz: solid lipid nanoparticles, microspheres. It may be noted that solid dispersion (SD) has exposed a highly potential strategy to augment 
the dissolution rate as well as the bioavailability of poorly soluble drugs. Solid dispersion is composed of at least two different compounds: a hydrophobic drug and a hydrophilic matrix. PVP loaded SD is generally produced by solvent evaporation method due to its high melting point $\sim 130^{\circ} \mathrm{C}$ (Zhai et al., 2017).

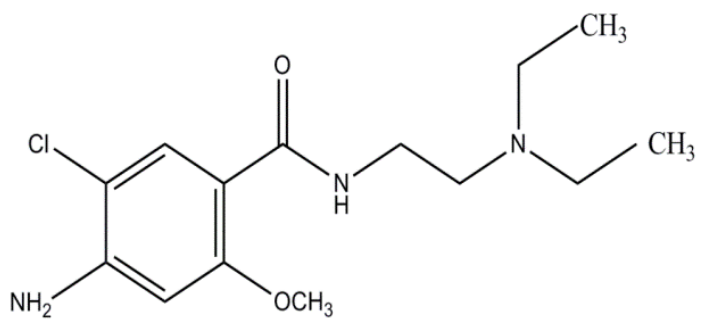

Fig. 1: Structure of metoclopramide.

By using UV detector lot of investigations were carried out for the purpose of detection of higher dose medications (Shidhaye et al., 2009). Lamparczyk and his co-workers (Lamparczyk et al., 2001) had developed a method to detect low amount of analyte in serum by HPLC with electrochemical detector. Most of the HPLC studies were accomplished with water soluble hydrochloride form of metoclopramide as dosage forms which are widely available in the market (Radwan, 1998; Deokate and Gorde, 2014; Shidhaye et al., 2009; Freudling and Vergin, 1983; Riley, 1984). Conversion of hydrochloride to base form causes deprotonation and gives rise to lipophilic form of metoclopramide. In case of minutely elevated incidence (frequency of disease) of undesirable effects due to any stability problem of drug dosage, high dose regimen has been coupled $(\sim 2$ $m g / K g$ ) with metoclopramide injection (I.V) that confers every 2 $\mathrm{h}$ interval of total five doses. The extrapyramidal symptoms, e.g. dystonic reactions, severe dyskinesias, Parkinsonism, akinesia, akathisia and neuroleptic malignant syndrome etc. occurred to be much typical for oral administration of high dose metoclopramide to adults (under thirty) as well as to adolescents (Riley, 1984). Some reports are also available based on simultaneous detection of metoclopramide along with other drugs (Vamsikrishna et al., 2014; Singh and Singh, 2012; Hegazy et al., 2013). There is dearth of report on HPLC method for the detection of low amount of metoclopramide base by UV detector.

The proposed method is developed and validated with metoclopramide base to study the comparison of recovery of pure metoclopramide and amount of metoclopramide extracted from PVP K30 based solid dispersion. Moreover, this method exerts a reversed phase high performance liquid chromatographic system which can be employed at ambient temperature having a small concentration of organic modifier in mobile phase. In this way, rapid, reliable, satisfactory and reproducible HPLC method was developed and various analytical evaluations were made for the validation of metoclopramide.

\section{MATERIALS AND METHODS}

\section{Reagents and Chemicals}

HPLC grade acetonitrile, water, acetone, glacial acetic acid and PVP K30 were purchased from Merck specialties Pvt.
Ltd., Germany. Metoclopramide hydrochloride was procured from Yarrow Chem. Products, Mumbai, India.

\section{Instrumentation}

The HPLC analysis was performed on WATERS high performance liquid chromatography knitted with 515 reciprocating single column HPLC pump and an injector MICROLITER ${ }^{\mathrm{TM}}$ \#710, HAMILTON Co. RENO, NEVADA with $0.10 \mathrm{~mL}$ sample loop, ZORBAX SB-C18 $(4.6 \times 250 \mathrm{~mm}, 5.0 \mu \mathrm{m})$ column as well as model 2487 dual $\lambda$ and absorbance detector.

\section{Preparation of mobile phase}

Mobile phase was prepared with acetonitrile (HPLC grade), methanol (HPLC grade) and water (HPLC grade) with a ratio of $25: 25: 50,30: 25: 45$ and 20:25:55 v/v/v. The $\mathrm{pH}$ of mobile phase was adjusted to $4.0,3.8$ and 4.2 with glacial acetic acid (HPLC grade) and the mobile phase was filtered with filter paper (Millipore $0.45 \mu \mathrm{m}$ ) to remove impurities.

\section{Sample preparation}

Stock solutions of Metoclopramide base were prepared by dispersing $10 \mathrm{mg}$ in mobile phase to produce $100 \mu \mathrm{g} / \mathrm{mL}$ of concentration. The solutions were diluted with mobile phase as required to make different standard solutions. $100 \mu \mathrm{L}$ of standard solution of each sample was injected to the HPLC column at flow rate of $1 \mathrm{~mL} / \mathrm{min}$. The total run time was observed as $8 \mathrm{~min}$ and the study was performed at $\lambda_{\max } 272 \mathrm{~nm}$.

\section{Conversion of Metoclopramide hydrochloride to Metoclopramide}

Requisite quantum (4 $\mathrm{gm})$ of Metoclopramide Hydrochloride (Met $\mathrm{HCl})$ was dissolved in known volume of double distilled water (DDW) and stirred well to get uniform dispersion. Sodium hydroxide solution $(1 \mathrm{NNaOH})$ was added to the solution drop wise to form metoclopramide base (Met base). The precipitate (Met base) was collected by filtration followed by washing with DDW for several times to remove excess $\mathrm{NaOH}$ and thereafter the wet precipitate was dried in a hot air oven at $50^{\circ} \mathrm{C}$. After that, the dried material was allowed to cool at $25^{\circ} \mathrm{C}$. In order to get purified and crystallized drug, the dried mass was added to $\sim 100 \mathrm{~mL}$ acetone (at boiling point, $56^{\circ} \mathrm{C}$ ) with constant stirring. The drug solution was filtered and kept at room temperature $\left(25^{\circ} \mathrm{C}\right)$. The solution was kept in a refrigerator for further cooling. Crystals were collected and dried in the hot air oven at $50^{\circ} \mathrm{C}$ until constant weight was attained. The material is cooled at room temperature $\left(25^{\circ} \mathrm{C}\right)$ and stored in a closed container away from light for further use. Metoclopramide is kept at room temperature owing to its storage condition. According to AFHS drug information 2010, (American Society of Hospital Pharmacists) metoclopramide must be stored at room temperature $20-25^{\circ} \mathrm{C}$.

\section{Differential Scanning Calorimetry (DSC) study}

Metoclopramide base as obtained after conversion from metoclopramide hydrochloride was scanned by UV-VIS spectrophotometer, and melting point was determined by DSC thermogram to check the purity of drug (Met base). DSC analysis of metoclopramide base was carried out in Perkins Elmer Instrument (Pyri's diamond TG/DTA) supported by a thermal analyzer. Approximately $10 \mathrm{mg}$ of Met base was placed in a sealed 
aluminium pan under nitrogen flow of $150 \mathrm{~mL} / \mathrm{min}$ and heated at a scanning rate of $10^{\circ} \mathrm{C} / \mathrm{min}$ over the temperature range of $30^{\circ} \mathrm{C}$ to $300^{\circ} \mathrm{C}$.

\section{Preparation of solid dispersion by solvent evaporation technique}

Solvent evaporation method was carried out by dispersing a physical mixture of metoclopramide and polymer (PVP K30) at certain ratio $(1: 3 \mathrm{w} / \mathrm{w})$ in a solvent mixture of dichloromethane and ethanol in a $(1: 1 \mathrm{v} / \mathrm{v})$ to form clear solution and subsequently it was left at ambient temperature for $24 \mathrm{~h}$ and the solvent was evaporated under vacuum until a solvent free thin layer of mass was obtained. The film was then dried under atmospheric condition until constant weight was achieved (Kalimuthu and Khanam, 2014).

\section{Extraction of metoclopramide from PVP K30- Metoclopramide solid dispersion}

PVP K30 is, as a matter of fact, hydrophilic synthetic carrier which is insoluble in acetone (NPCS Board of Engineers, 2009) but metoclopramide is readily soluble in acetone. Known amount of dried mass of PVP K30-metoclopramide (3:1 w/w) solid dispersion was added in accordance with required volume of acetone and stirred for uniform mixing of drug. It was forthwith observed that precipitation of PVP K30 was formed. Suitable dilution is prepared and an aliquot $(0.10 \mathrm{~mL})$ is injected to the system.

\section{Method development}

In this section, the detailed explanation of the proposed method is presented. The total framework of the proposed method is elucidated in Figure 2.

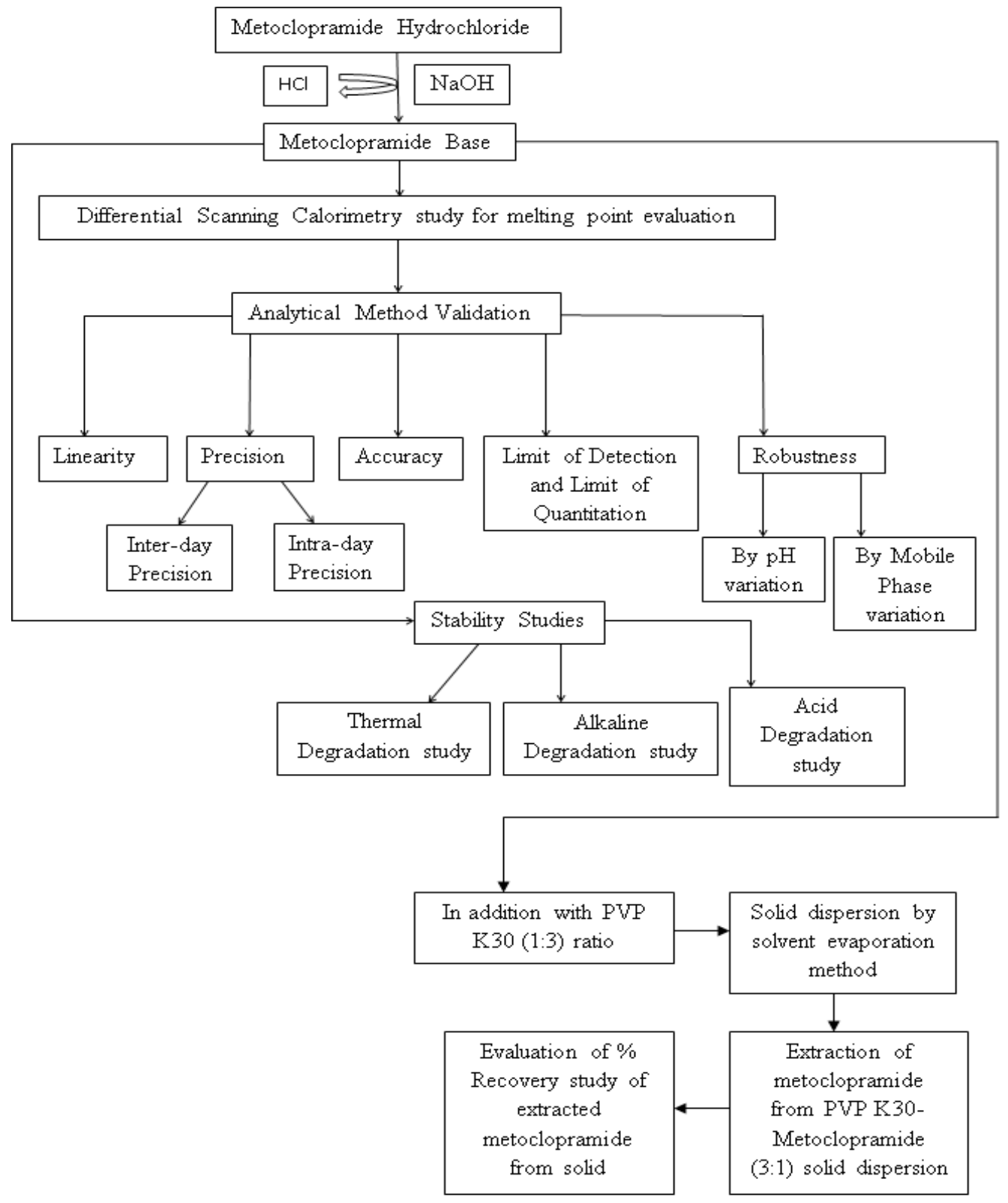

Fig. 2: Framework of the proposed method. 


\section{METHOD VALIDATION}

The present study emphasizes on the development of HPLC method for metoclopramide base as per ICH guideline (Q2 (R1)) (1994).

The proposed analytical method was validated in terms of several parameters e.g. linearity and range, accuracy, inter and intra-day precision, limit of detection (LOD), limit of quantitation (LOQ), and robustness. These parameters are described in detail in the method validation section.

\section{Method Validation}

\section{Linearity}

Linearity is the propensity of a technique to generate test effects which are directly proportionate to the concentration of analyte within the given range. In analytical method, range is defined as an interval between the upper and lower extent of analytes in the sample for which it has been ascertained that the method is appropriated with accuracy, precision and linearity applying the procedure as discussed. A stock solution of metoclopramide at a concentration of $100 \mu \mathrm{g} / \mathrm{mL}$ was prepared. From the stock solution a range of dilutions $(2-20 \mu \mathrm{g} / \mathrm{mL})$ were made and filtered. Each sample of $100 \mu \mathrm{L}$ was injected to the HPLC column. Data obtained from area of chromatograms were plotted against respective concentrations.

\section{Precision}

Inter-day and intra-day precision studies were performed to check variations in short and long term period. Nine samples from different standard solutions were made and thereafter the samples of prepared solution $(10 \mu \mathrm{g} / \mathrm{mL}$ concentration and 100 $\mu L$ volume) were injected one by one at regular interval. The chromatograms for each solution were recorded at $\lambda_{\text {max }} 272 \mathrm{~nm}$. In case of 'intra-day', the above study was repeated in the same day at different time intervals as per the guideline, while for the inter-day precision study, three different standard solutions were made in three days and proper dilutions were made to get the final concentration of $10 \mu \mathrm{g} / \mathrm{mL}$. Three sample solutions of same volume were evaluated one after another at different time intervals. The chromatograms were recorded for each sample. Column (HPLC) was washed before and after each evaluation.

\section{Accuracy}

Accuracy reveals the closeness of agreement between the values accepted either as a conventional true value and the value actually found. To evaluate accuracy of the HPLC method, recovery study was conducted. The parameter accuracy (recovery) of pure metoclopramide and extracted Met base were ascertained by the analysis of spiked samples having different concentrations of $4 \mu \mathrm{g} / \mathrm{mL}, 10 \mu \mathrm{g} / \mathrm{mL}$ and $16 \mu \mathrm{g} / \mathrm{mL}$ and $6 \mu \mathrm{g} / \mathrm{mL}$ as well as 10 $\mu g / m L$ respectively. Percentage recovery was calculated by area obtained experimentally and area from standard curve.

\section{Limit of detection and limit of quantitation}

The proposed method validation can be assessed by calculating the limit of detection (LOD) and limit of quantitation (LOQ). In order to enumerate the LOD and LOQ the following formulae were used, $\mathrm{LOD}=3.3 \sigma / S, \mathrm{LOQ}=10 \sigma / S$, respectively in accordance with ICH guidelines, where $\sigma$ is the standard deviation of peak area of placebo 901.30 and $S$ is the slope of standard curve 56616. The standard curve is depicted in Figure 4.

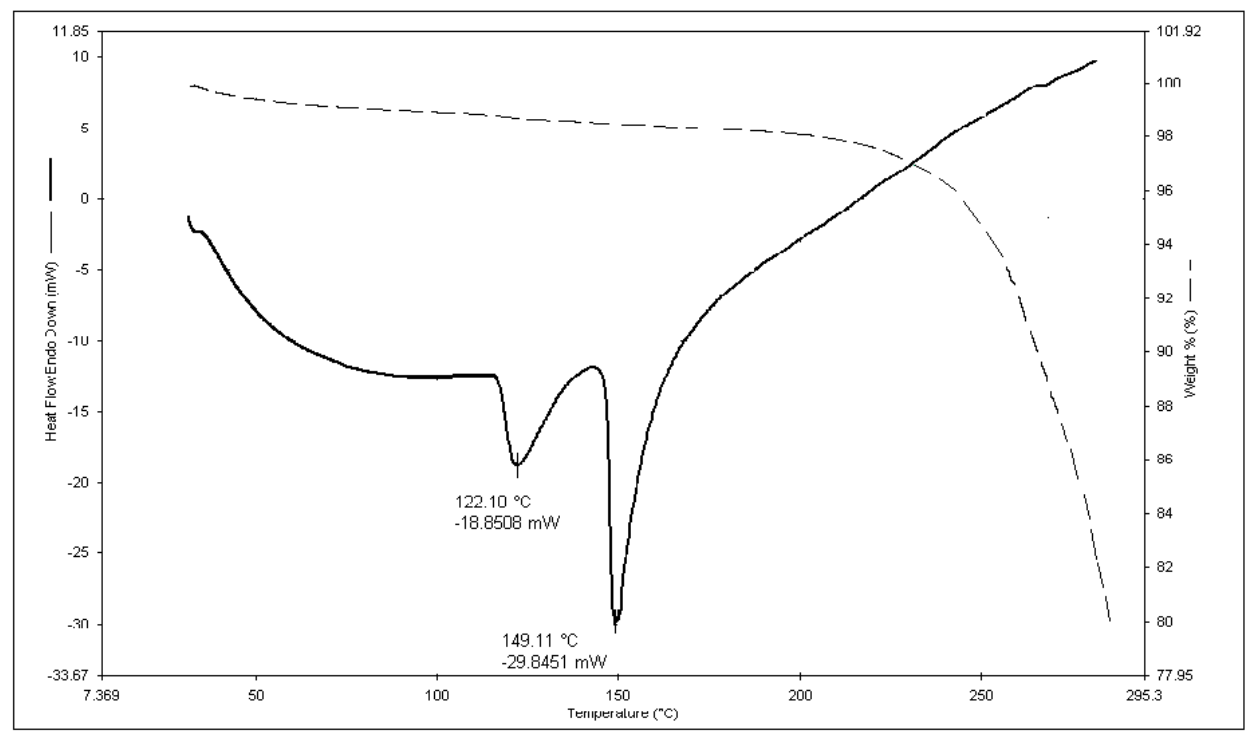

Fig. 3: DSC thermogram of metoclopramide base.

\section{Robustness}

Robustness analysis was accomplished to verify the sensitiveness of the method. Robustness and stability were checked by keeping the sample of drug at different conditions. HPLC method assessment of robustness was done by changing different parameters like: composition of mobile phase and $\mathrm{pH}$ of mobile phase. To evaluate the effect, observation was completed by changing one parameter at one time. On the basis of significant responses, (low values of \%RSD) robustness was confirmed. 


\section{Stability Studies}

It is important to assess purity of a drug substance and also to understand impurities, if any, generated by the method of preparation, storage condition and the influence of method variables during analysis of impurities present in raw material (Jones et al., 2013). Published an article on ACQUITY UPC ${ }^{2}$ system to analyze metoclopramide and related impurities by MS spectral data. Method development can be improved by investigating properties of impurities. The stability study of the proposed method can be assessed by thermal, alkaline and acid degradation assay.

Study of thermal degradation of metoclopramide base: Effect of temperature on the degradation of metoclopramide base was observed at $100^{\circ} \mathrm{C}$. Accurately weighed metoclopramide base $(\sim 100 \mathrm{mg})$ was kept in a hot air oven for $24 \mathrm{~h}$. After $24 \mathrm{~h}$. the drug was dissolved in $10 \mathrm{~mL}$ methanol and volume was made upto $100 \mathrm{~mL}$ with mobile phase. The solution was further diluted with mobile phase (acetonitrile: methanol: water, 25:25:50 v/v/v) to get the final concentration of $10 \mu \mathrm{g} / \mathrm{mL}$. The sample $(100 \mu \mathrm{L})$ was injected to the HPLC column.

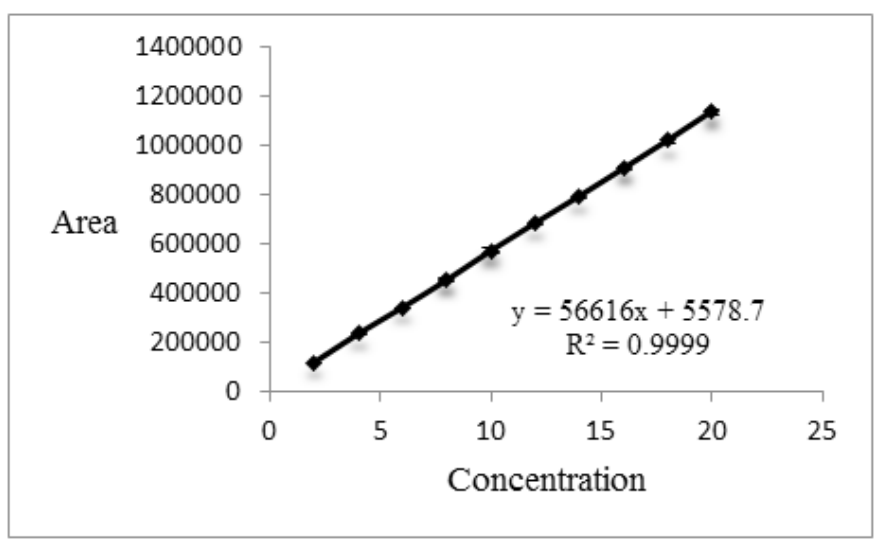

Fig. 4. Standard curve of Metoclopramide Base.

Study of Alkaline degradation of metoclopramide base: Forced degradation of metoclopramide base in alkaline media was brought about by addition of $10 \mathrm{mg}$ of metoclopramide base with small amount of HPLC graded methanol $(1 \mathrm{~mL})$ and after that 0.1 $\mathrm{N} \mathrm{NaOH}$ was added to it to make up the volume upto $10 \mathrm{~mL}$ and the alkaline drug solution was kept in water bath at $60^{\circ} \mathrm{C}$ for 24 h. The solution was left to ambient temperature $\left(25^{\circ} \mathrm{C}\right)$ and its neutral $\mathrm{pH} 7.0$ was maintained by the addition of $0.1 \mathrm{~N} \mathrm{HCl}$ and it was diluted to $100 \mathrm{~mL}$ with mobile phase (acetonitrile: methanol: water $25: 25: 50 \mathrm{v} / \mathrm{v} / \mathrm{v}$ ) to make the final concentration of $10 \mu \mathrm{g} / \mathrm{mL}$.

Study of Acid degradation of metoclopramide base: Degradation by acid was accomplished by addition of required volume of methanol to $10 \mathrm{mg}$ Met base and afterwards $0.1 \mathrm{~N} \mathrm{HCl}$ was added to adjust the volume up to $10 \mathrm{~mL}$ and left the drug solution in water bath at $60^{\circ} \mathrm{C}$ till $24 \mathrm{~h}$. The solution was kept at room temperature $\left(25^{\circ} \mathrm{C}\right)$ and neutralized to $\mathrm{pH} 7.0$ and it was diluted to $100 \mathrm{~mL}$ with mobile phase in order to get the final concentration of $10 \mu \mathrm{g} / \mathrm{mL}$.

\section{RESULTS AND DISCUSSION}

Effect of polar solvent (methanol, water) on retention time was found interesting. At $\mathrm{pH} 4.0$ with mobile phase compositions of 30:25:45, 25:25:50 and 20:25:55 v/v/v, $\mathrm{R}_{\mathrm{T}}$ was found 3.69, 3.891 and $4.1 \mathrm{~min}$ respectively. With the increase of total fraction of polar solvents with respect to acetonitrile it takes slightly more time to elute and so, there was increase in retention time as the propensity of Met base molecules $(\log p=2.08)$ has more affinity for stationary phase. Acetonitrile is a polar aprotic solvent with high dielectric constant and high dipole moment and it has capability of forming hydrogen bonding which strengthens degree of elution when acetonitrile is used as mobile phase. For mobile phase, the lower the absorbance of acetonitrile, the lower the noise in UV detection and this tendency best matches for high sensitivity analysis at short UV wavelength.

(Lamparczyk et al., 2001) observed meticulously the effect of composition of solvents (acetonitrile and methanol) on the separation efficiency of metoclopramide. They reported that with increase percentage of acetonitrile (30-60\%) the retention of Met base on the C18 stationary phase was very low and unsatisfactory peak widths were observed for lower concentration of acetonitrile $(<30 \%)$, and low retention occurred at high concentration of methanol in mobile phase. Therefore, composition of multiple solvents in mobile phase should be judiciously selected to make a good balance among retention time and peak width.

The present method for metoclopramide base is found rapid as its retention time is $\sim 3.8 \mathrm{~min}$ and total clean up does not require much time when long clean up period $(7 \mathrm{~h})$ was reported earlier by (Freudling and Vergin, 1983). The method is simple as mobile phase is prepared without any complexity and it is not labor intensive. The running cost is also very low.

In DSC study, two endotherms of metoclopramide base were found at $122^{\circ} \mathrm{C}$ and $149^{\circ} \mathrm{C}$ Figure 3. Mitchell (Mitchell, 1985 ) opined that the DSC profile of Met base exists as two enantiotropic polymorphs, and the transition of the Form I (stable at room temperature, $22^{\circ} \mathrm{C}$ ) to stable Form II occurs rapidly at $125^{\circ} \mathrm{C}$ and Form II melts at $147^{\circ} \mathrm{C}$. But in this study two forms of enantiotropic polymorphs were observed at $122^{\circ} \mathrm{C}$ and $149^{\circ} \mathrm{C}$ due to purification (crystallization) of Met base.

Wang (Wang et al., 2011) studied the thermal effect on solid state characterization of metoclopramide hydrochloride monohydrate $\left(\mathrm{MCP}, \mathrm{H}_{2} \mathrm{O}\right.$ ) by DSC, TG and thermally responsive FTIR micro spectroscopy, and they explained the changes occurred owing to process of dehydration (loss of $\mathrm{H}_{2} \mathrm{O}$ ), amorphization and recrystallization as evidenced by endothermic peak at $85^{\circ} \mathrm{C}$, at $184^{\circ} \mathrm{C}$ (melting point of $\mathrm{MCP}, \mathrm{H}_{2} \mathrm{O}$ ) and exothermic peak at $105^{\circ} \mathrm{C}$ are possibly related to the recrystallization of amorphous sample. The above studies highlight the fact that the changes may occur in solid state characteristics during milling, wet granulation and drying due to dehydration or desolvation or polymorphic transformation of API; and it leads to alteration in physicochemical properties and bioavailability of APIs.

The proposed HPLC method brings forward an outstanding standard curve. Linearity was found between the concentration of Met base and area of peaks with correlation coefficient $\left(R^{2}\right)=0.999$ and $y=56616 x+5578(n=3)$. 
The $\% \mathrm{RSD}$ for inter-day and intra-day reproducibility of the analysis was found to be $0.07-2.46 \%$ and $3.10 \%$ respectively. The results of inter-day and intra-day precision are presented in Table 1.

Table 1: Study of Inter-day and Intra-day precision (for each data of Inter-day precision $\mathrm{n}=3$, for Intra-day precision, $\mathrm{n}=9$ ).

\begin{tabular}{lcccccc}
\hline & \multicolumn{3}{c}{ Inter-day precision } & \multicolumn{3}{c}{ Intra-day precision } \\
\hline Sl. No. & $\begin{array}{c}\text { Avg. RT } \\
(\mathbf{m i n})\end{array}$ & $\begin{array}{c}\text { Conc. } \\
(\boldsymbol{\mu} / \mathbf{m L})\end{array}$ & \%RSD & $\begin{array}{c}\text { Conc. } \\
(\boldsymbol{\mu g} / \mathbf{m L})\end{array}$ & $\begin{array}{c}\text { Avg. RT } \\
(\mathbf{m i n})\end{array}$ & $\%$ RSD \\
\hline Day 1 & 3.94 & 10 & 2.46 & & & \\
Day 2 & 3.30 & 10 & 0.07 & 10 & 3.36 & 3.10 \\
Day 3 & 3.29 & 10 & 0.18 & & & \\
\hline
\end{tabular}

LOD and LOQ of blank samples were found to be 0.052 $\mu \mathrm{g} / \mathrm{mL}$ and $0.159 \mu \mathrm{g} / \mathrm{mL}$ respectively under developed HPLC
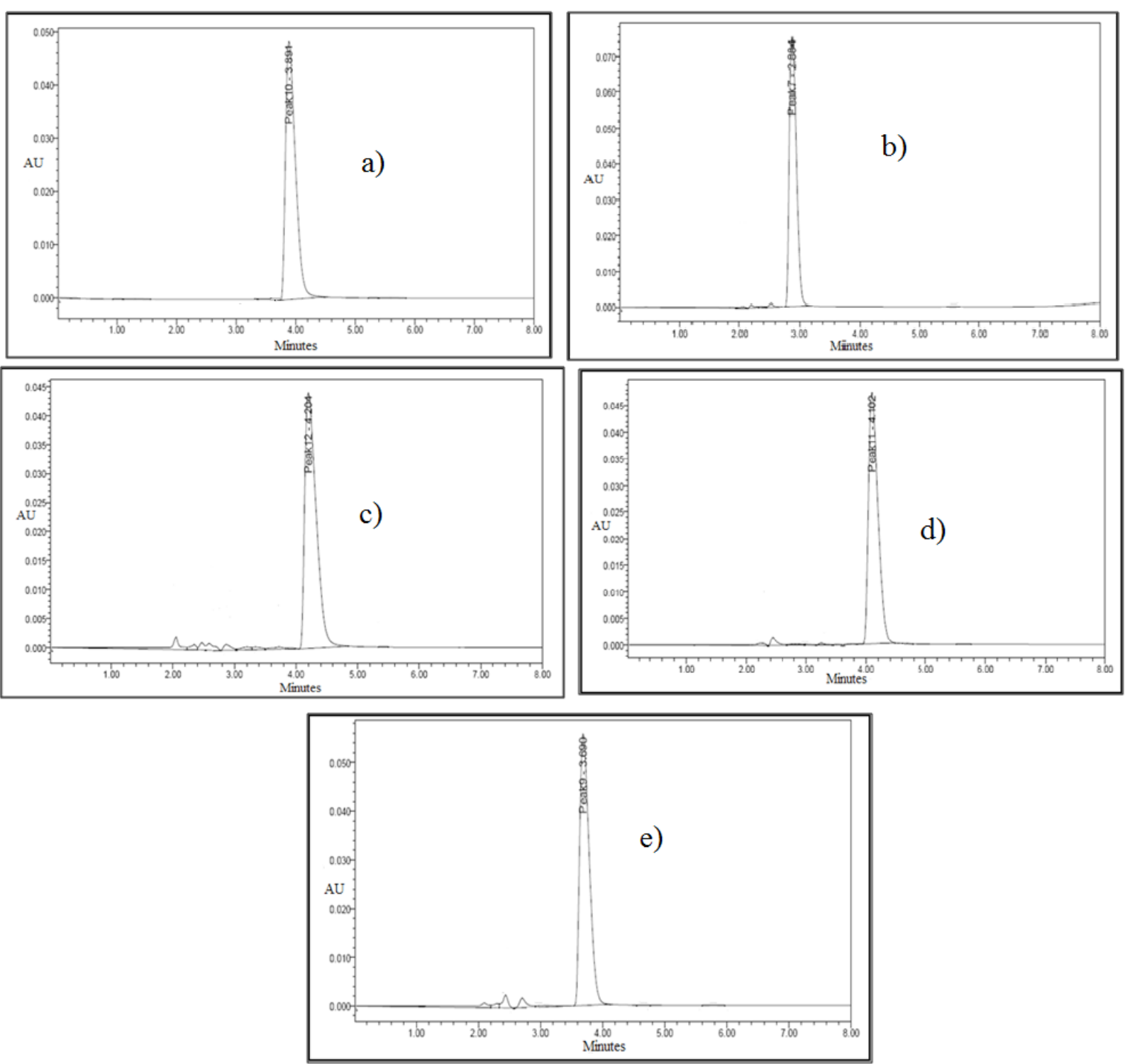

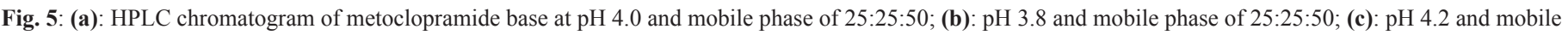
phase of 25:25:50; (d): mobile phase 20:25:55 and pH 4.0; (e): mobile phase 30:25:45 and pH 4.0.

condition. The LOD and LOQ values for the proposed method provide satisfactory results.

The robustness study Figure 5 a-e yields sharp peaks having symmetrical and harmonious arrangements by using an acidic mobile phase in reverse phase $\mathrm{C} 18$ column. As methanol dissolves drug in decent manner, it was the right one to choose as an organic solvent. Composition of acetonitrile, methanol and water with the proportion of 25:25:50 and 20:25:55 v/v/v at $\mathrm{pH} 4.0$ and $\mathrm{pH} 3.8$ yields clear resolutions but in $\mathrm{pH} 4.2$ and mobile phase 30:25:45 v/v/v slight noises were observed possibly due to generation of any polar/salt forms during the procedure. With slight variation of $\mathrm{pH}$, retention time changes appreciably. Fadden and his co-workers (Fadden et al., 2006) used Monolithic column which had shown reduced retention time, from 18.3 to $3.8 \mathrm{~min}$ resulting in rapid separation without sacrificing column efficiency.

e) 
The results of robustness validation is illustrated in Table 2. Theoretical plates and tailing effects calculated for each figure are narrated in Table 3.

Table 2: Robustness method validation.

\begin{tabular}{cccc}
\hline \multicolumn{4}{c}{ Robustness study } \\
\hline Condition & $\begin{array}{c}\text { Avg. RT (min) } \\
\mathbf{n}=\mathbf{3}\end{array}$ & Conc. $(\boldsymbol{\mu g} / \mathbf{m L})$ & \% RSD \\
\hline pH 3.8* & 2.69 & 10 & 0.23 \\
pH 4.0 & 3.94 & 10 & 2.46 \\
pH 4.2 & 4.21 & 10 & 0.90 \\
$1: 1: 2$ or $25: 25: 50^{* *}$ & 3.94 & 10 & 1.23 \\
$6: 5: 9$ or 30:25:45 & 3.65 & 10 & 1.40 \\
$4: 5: 11$ or $20: 25: 55$ & 4.06 & 10 & 0.45 \\
\hline
\end{tabular}

${ }^{*} \mathrm{pH}$ of sample $(3.8,4.0$ and 4.2$)$ at fixed mobile phase composition (acetonitrile, methanol, water, 25:25:50 v/v/v).

$* *$ mobile phase composition volume wise (acetonitrile, methanol, water,

$25: 25: 50,20: 25: 5530: 25: 45 \mathrm{v} / \mathrm{v} / \mathrm{v})$, at fixed $\mathrm{pH} 4.0$ of sample.

Suleiman (Suleiman et al., 1989) and his co-authors developed HPLC method for metoclopramide hydrochloride at ambient temperature using $\mathrm{C}_{8}$ reversed-phase column with a mobile phase consisting of phosphate buffer (10 mM)-methanolacetonitrile $(50 \%+28 \%+22 \%)$ at a flow-rate of $1.5 \mathrm{~mL} /$ min adjusted to $\mathrm{pH} 4.8$. They reported the retention time for metoclopramide hydrochloride as $7.5 \mathrm{~min}$. (Singh and Singh, 2012) carried out HPLC analysis in a mixture of drugs in which reported retention time for metoclopramide hydrochloride was longer $(10.8 \mathrm{~min})$. Duration of retention time depends on many factors such as: physicochemical properties of testing sample, solvents, flow rate, temperature, $\mathrm{pH}$, column pressure and column characteristics.

Table 3: Theoretical plates and tailing effect of mentioned figures (4(a)-4(e)).

\begin{tabular}{ccc}
\hline Sl. No. & Theoretical plates & Tailing factors \\
\hline Figure 5a & 2616 & 1.25 \\
Figure 5b & 3462 & 0.85 \\
Figure 5c & 2434 & 1.2 \\
Figure 5d & 3199 & 1.1 \\
Figure 5e & 2698 & 1.25 \\
\hline
\end{tabular}

In accuracy method validation $\%$ Recovery is found to be substantively complete $(\sim 100 \%)$ and not dependent on concentration. Whereas, the chromatogram of isolated metoclopramide base Figure 6 from the SD matrix showed well resoluted sharp peak with $\mathrm{R}_{\mathrm{T}} 3.056 \mathrm{~min}$. which is approximately close to the retention time of pure metoclopramide. The $\%$ recovery results of pure and extracted metoclopramide are presented in Table 4.

Table 4: Recovery study of pure and extracted Met base.

\begin{tabular}{|c|c|c|c|c|c|c|}
\hline Concentration of pure Met base $(\mu \mathrm{g} / \mathrm{mL})$ & Avg. RT & $\%$ RSD & \% Recovery & Concentration of extracted Met base $(\mu \mathrm{g} / \mathrm{mL})$ & Avg. RT & $\%$ Recovery \\
\hline $4(n=3)$ & 3.46 & 1.04 & 105.10 & $6(n=3)$ & 3.05 & 86.55 \\
\hline $10(n=3)$ & 3.35 & 0.49 & 103.61 & $10(n=3)$ & 3.04 & 120 \\
\hline $16(n=3)$ & 3.32 & 0.06 & 103.44 & & & \\
\hline
\end{tabular}

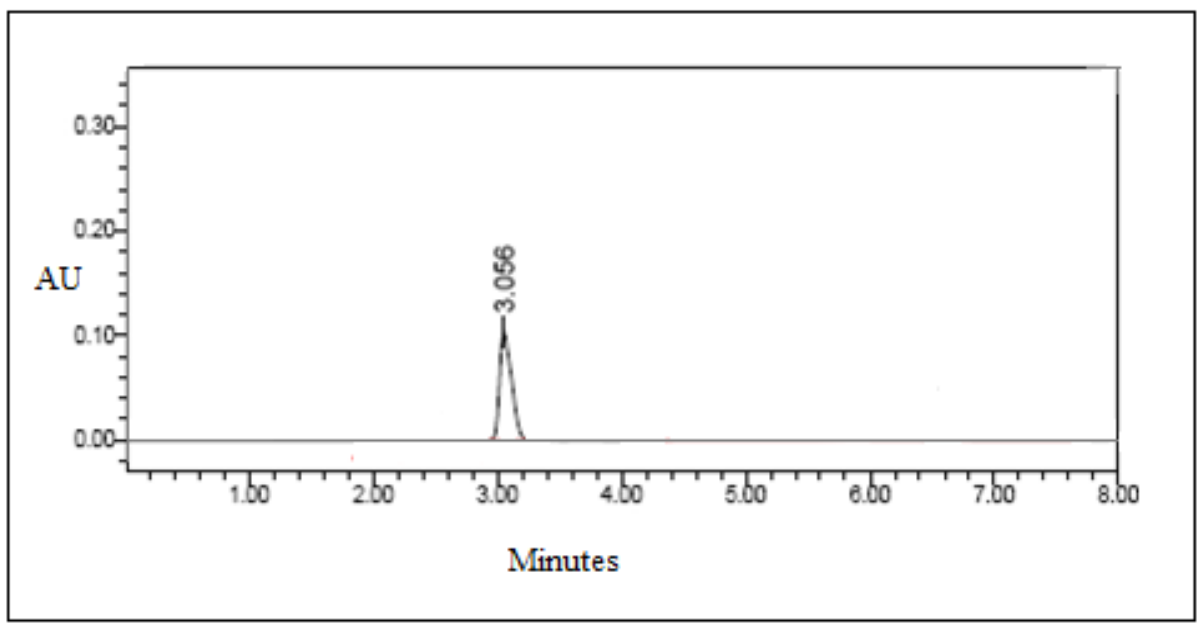

Fig. 6: Chromatogram of extracted metoclopramide from PVP K30 based solid dispersion.

Recovery of Met base from SD was necessarily quantitative and notably there was no effect of polymer/ excipient existing in the formulation and thus clear elution of metoclopramide is confirmed. However, an error may occur in respect of recovery of Met base $(\sim 120 \%)$ from SD likely due to the adsorption of Met base upon glass or because of experimental errors occurred at the time of weighing (taken into account during formulation studies later on).

The number of theoretical plates for extracted metoclopramide was found higher than pure metoclopramide $N=$ 4927 which proved good column efficiency.

Stability of the HPLC method confirmed to be selective. 
In thermal effect Figure 7 (a) no significant degradation of metoclopramide was observed. The $\mathrm{pKa}$ value of metoclopramide base is 9.42 , which indicates that the metoclopramide base remains in unionized and it is comparatively more stable in basic $\mathrm{pH}$. In this assay also no degradation was observed. Chromatogram of alkaline degradation is depicted in Figure 7 (b).

Solubility of metoclopramide benzamide increases with acidity (pH 7.4 solubility $\sim 1.37 \mathrm{mg} / \mathrm{mL}, \mathrm{pH} 6.8$ solubility $\sim 3.36 \mathrm{mg}$ / $m L$, pH 5.5 solubility $\sim 5.55 \mathrm{mg} / \mathrm{mL}$ at $37^{\circ} \mathrm{C}$ ) owing to its ionization to some extent. This fact favors elution of adsorbed metoclopramide from stationery phase by a polar solvent when $\mathrm{pH}$ is acidic.

The major degradation of drug was observed in case of forced acid hydrolysis when the drug was associated with $0.1 \mathrm{~N}$
$\mathrm{HCl}$ for a long period at elevated temperature; the chromatogram Figure 8 revealed two peaks with $\mathrm{R}_{\mathrm{T}}, 2.935 \mathrm{~min}$ and $4.477 \mathrm{~min}$ and corresponding \% Area of 12.17 and 26.63 indicating the formation of degraded products. Metoclopramide, being a base behaves as moderately strong Bronsted base in presence of mineral acids, and as generally benzamide derivatives consist of different active groups such as amide $(-\mathrm{CONH})$, primary amine $\left(-\mathrm{NH}_{2}\right)$, and tertiary amine $\left(\mathrm{R}_{3}-\mathrm{N}\right)$, it gets protonated in specific condition, but the site of attachment of proton (amino nitrogen and carboxylic oxygen) had been a conflictive point as argued by many investigators. While some of them strongly suggested O-protonation owing to resonance stabilization, other group supported the view that $\mathrm{N}$-protonation as $\pi$ electrons are not delocalized.
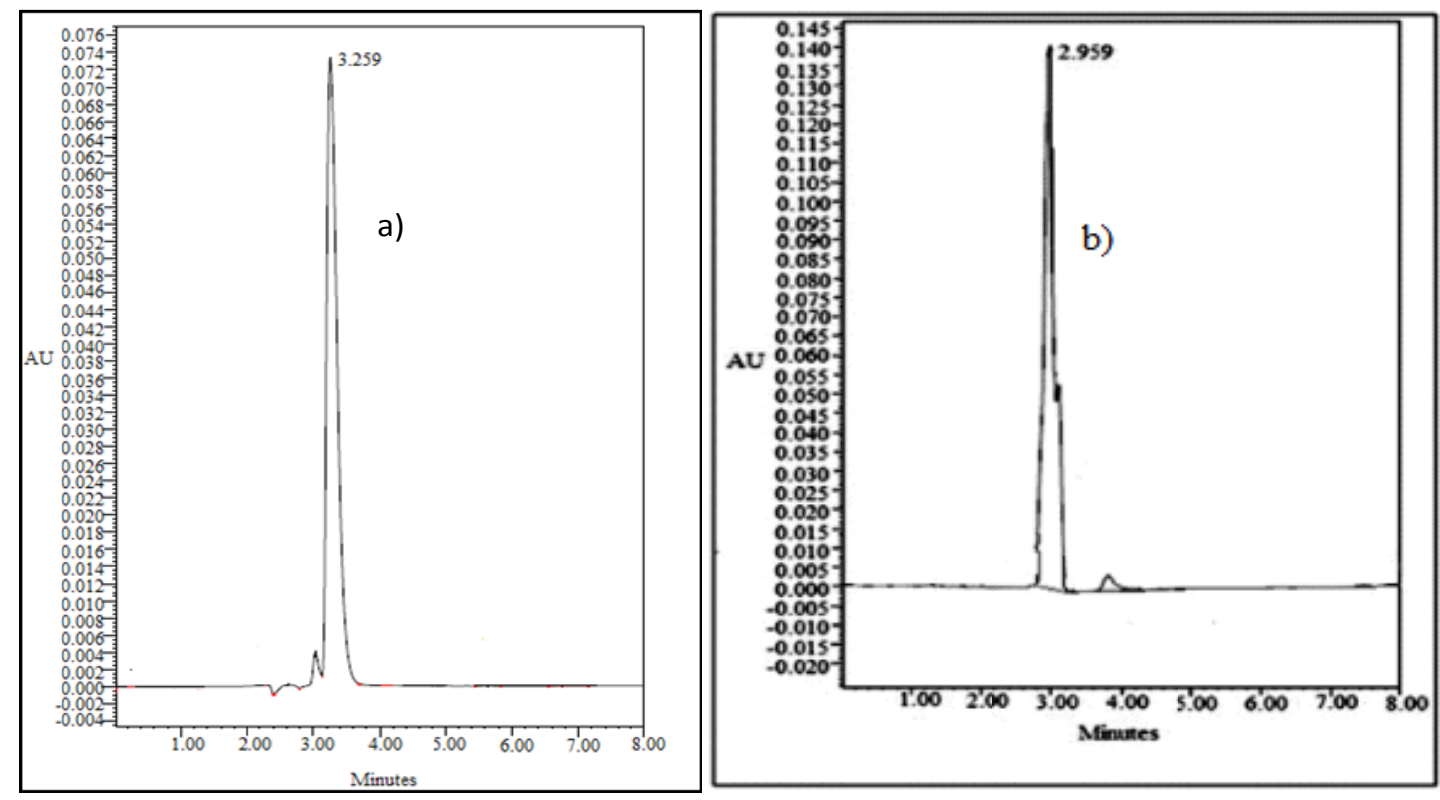

Fig. 7: (a): HPLC Chromatogram of Metoclopramide base after thermal degradation; (b): alkaline degradation.

Authors, (Edward et al., 1960; Sawale et al., 2016; Stojkovi and Popovski, 2006; Catalan and Yanez, 1980) predicted protonation site in benzamides by theoretical study and established O-protonation on the basis of 'gas phase basicity' and N-protonation based on 'solvent phase basicity' as charge is localized on amino group containing a lone pair of electrons, being attached with the electron repelling alkyl groups. Charge density on secondary nitrogen is comparatively lower than that of tertiary one as it is attached to electron withdrawing carboxylic oxygen which in turn gets protonated in acidic $\mathrm{pH}$ and subsequently reacts strongly with water molecule. Maquille and his co-investigator (Maquille and Jiwan, 2009) studied on LC-MS characterization of metoclopramide photolysis products and they identified 18 photolysis products. Among them, the one product named diethylamine $\left(\mathrm{CH}_{3} \mathrm{CH}_{2}\right)_{2} \mathrm{NH}^{+} \mathrm{CH}_{2} \mathrm{CH}_{2} \mathrm{NH}_{2}$, shows that this molecule possessed a similar lateral chain as metoclopramide.

On the basis of the knowledge of investigations the earlier researchers suggested that forced hydrolysis of metoclopramide in acidic medium at elevated temperature causes a breakage at the carboxylic junction of the drug molecules and degraded products of carboxylic acid (4-amino-5-chloro-2-methoxybenzoic acid) and N,Ndietylethane-1,2-diamine are possibly formed (Cox and Yates, 1981).

\section{CONCLUSION}

The wide range of bioavailability makes metoclopramide a difficult drug to use orally. So a reliable, rapid and reproducible analytical method is developed to detect low concentration of Met base. This is the new method in literature to quantify Met base in matrix of SD. The method ensures the stability of the product during analysis as the $\mathrm{pH}$ of the medium for analysis is kept at the optimum i.e. $\mathrm{pH} 4.0$ that results well resoluted peak with retention time around $4 \mathrm{~min}$ which also needs short run time $(<10$ min $)$ cost-effective for the pharmaceutical industry. Solid dispersion of metoclopramide is satisfactorily prepared using PVP K30 as hydrophilic polymer. The recovery and column efficiency were increased dramatically as compared to the pure drug (Met base). HPLC method validation requires checking up of some well guided tests, for example: accuracy, precision, linearity, limit of detection, limit of quantification, robustness so that the method may be applied in practical cases. It effectively separates the pure metoclopramide and also yields clear and sharp peak for extracted metoclopramide from the matrix of SD. This method is robust with mobile phases of small variation and swift run time $(8 \mathrm{~min})$ and comparatively low flow rate $(1 \mathrm{~mL} / \mathrm{min})$ of mobile phase that helps the study for large scale and within low cost. So, the present 
HPLC analysis method can be utilized for the investigation of low quantity of metoclopramide in biological fluid.

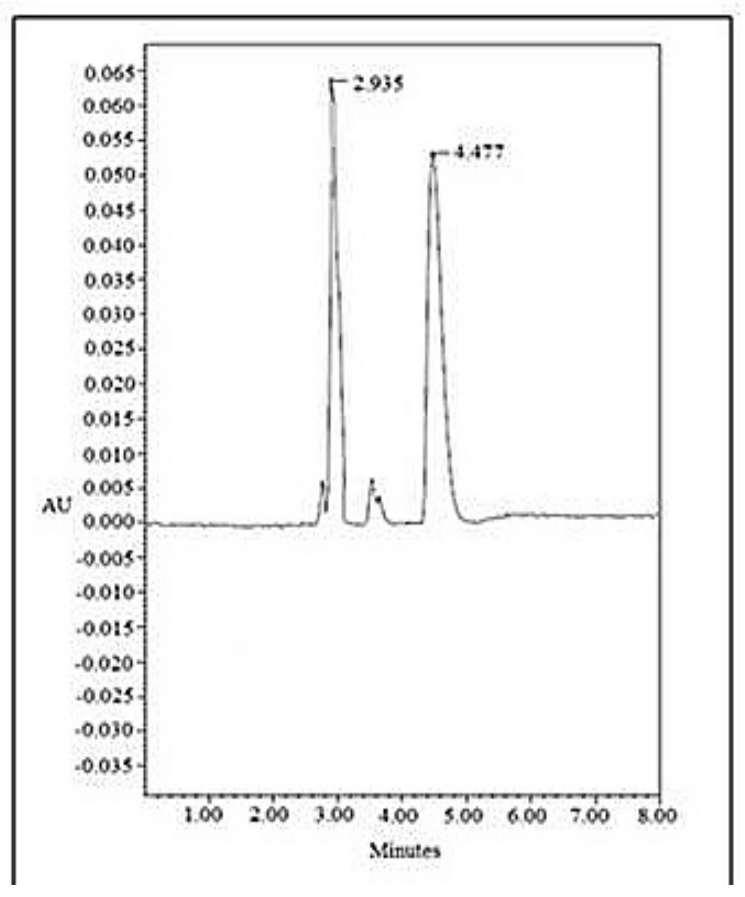

Fig. 8: HPLC Chromatogram of Metoclopramide base after acid degradation study.

\section{CONFLICT OF INTEREST}

The authors declare that they have no conflict of interest.

\section{REFERENCES}

AFHS drug information 2010. [ONLINE] Available at: https:// pubchem.ncbi.nlm.nih.gov/compound/metoclopramide.

Catalan J, Yanez M. A theoretical study on the protonation of benzamide. Tetrahedron, 1980; 36:665-667.

Cox RA, Yates K. The hydrolyses of benzamides, methyl benzimidatium ions, and lactams in aqueous sulfuric acid. The excess acidity method in the determination of reaction mechanisms. Can J Chem, 1981; 59: 2853-2863.

Deokate UA, Gorde AMA. Stability indicating UV spectrophotometric method for determination of metoclopramide hydrochloride. Int J Pharm and Pharm Sci, 2014; 6:394-397.

Edward JT, Chang HS, Yates K, Stewart R. Protonation of the amide group: I. the basicities of substituted benzamide. Can J Chem, 1960; 38:1518-1525.

Fadden MK, Gillespie J, Carney B, O'Driscoll D. Development and application of a high-performance liquid chromatography method using monolithic columns for the analysis of ecstasy tablets. J Chromat A, 2006; 1120:54-60.

Freudling B, Vergin H. Determination of metoclopramide in human plasma by high performance liquid chromatography. J Chromat B, $1983 ; 273: 453-457$.

Hegazy AM, Loebenberg R, Hassan NY, Metwally FH, AbdelKawy M. Studying the compatibility of a metoclopramide- $\mathrm{HCl}$-paracetamol mixture via IHCMC and establishing a validated RP-HPLC method for its determination in tablets. Anal Methods, 2013; 5:3714-3720.

ICH guideline (Q2(R1)). 1994. http://www.ich.org.

Jones MD, Aubin A, Hong P, Potts W. 2013. Waters Corporation. Milford. MA. USA.

Jones SA, Martin GP, Brown MB. Determination of polyvinyl pyrrolidone using high- performance liquid chromatography. J Pharm and Biomed Anal, 2004; 35:621-624.

Kalimuthu Y, Khanam J. Enhancement of carvedilol solubility by solid dispersion technique using cyclodextrins, water soluble polymers and hydroxyl acid. J Pharm Biomed Anal, 2014; 96:10-20.

Lamparczyk H, Chmielewska A, Konieczna L, Plenis A, Zarzycki, KP. RP-HPLC method with electrochemical detection for the determination of metoclopramide in serum and its use in pharmacokinetic studies. Biomed Chromatography, 2001; 15:513-517.

Maquille A, Jiwan J-LH. LC-MS characterization of metoclopramide photolysis products. J Photochem and Photobiol A: Chemistry, 2009; 205:197-202.

Mitchell AG. Polymorphism in metoclopramide hydrochloride and metoclopramide. J Pharm Pharmacol, 1985; 37:601-604.

NPCS Board of Consultants \& Engineers. 2009. Handbook on textile auxiliaries, dyes and dye intermediates technology. Asia Pacific Business Press Inc.

Radwan MA. Determination of metoclopramide in serum by HPLC assay and its application to pharmacokinetic study in rat. Anal Letters, 1998; 31:2397-2410.

Riley CM. The determination of metoclopramide in plasma by reversed-phase ion-pair high-performance liquid chromatography. J Pharm \& Bio. Anal, 1984; 2:81-89.

Ritter JM, Lewis LD, Mant TGK, Ferro A. 2008. A Text Book of Clinical Pharmacology and Therapeutics. United Kingdom (UK), Great Britain. Sawale RT, Kalyankar TM, George, R, Deosarkar SD. Molarrefraction and polarizability of antiemetic drug 4-amino-5-chloro-N(2-(diethylamino)ethyl)-2 methoxybenzamide hydrochloride monohydrate in \{Aqueous-Sodium or Lithium Chloride\} solutions at $30^{\circ} \mathrm{C}$. J App Pharm Sci, 2016; 6:120-124.

Shakeel F, Shazly GA, Nazrul H. Solubility of metoclopramide hydrochloride in six green solvents at (298.15 to 338.15$) \mathrm{K}$. J Chem and Engg Data, 2014; 59:1700-1703.

Shidhaye S, Malke S, Kadam V. Development and validation of stability indicating HPLC method for estimation of metoclopramide hydrochloride from a novel formulation. J Pharm Res, 2009; 2:290-295.

Singh A, Singh BS. Simultaneous estimation of sumatriptan succinate, metoclopramide hydrochloride and paracetamol by RP-HPLC method. J Pharm Sci and Res, 2012; 4:1848-1851.

Stojkovi G, Popovski E. Determination and structural correlation $\mathrm{pK}_{\mathrm{BH}}{ }^{+}$for meta- and para- substituted benzamides in sulfuric acid solutions. J Serb Chem Soc, 2006; 71:1061-1071.

Suleiman MS, Najib MN, el-Sayed YM, Badwan A. Stabilityindicating high-performance liquid chromatographic assay for the determination of metoclopramide hydrochloride in pharmaceutical dosage forms. Analyst, 1989; 114:365-368.

Vamshikrishna G, Neelima M, Bhavani M, Sreekanth G, Shobha Rani S. A simple RP-HPLC method for simultaneous estimation of paracetamol and metoclopramide $\mathrm{HCl}$ in tablet dosage form. IOSR J Pharm and Biol Sci, 2014; 9:69-78.

Wang SL, Wong YC, Cheng WT, Lin SY. A continuous process for solidstate dehydration, amorphization and recrystallization of metoclopramide HCL monohydrate studied by simultaneous DSC-FTIR micro-spectroscopy. J Ther Anal and Calori, 2011; 104:261-264.

Zhai X, Li C, Lenon GB, Xue CCL, Li W. Preparation and characterization of solid dispersions of tanshinone IIA, cryptotanshinone and total tanshinones. Asian J Pharm Sci, 2017; 12:85-97.

How to cite this article:

Kahali N, Khanam J. A Novel HPLC Method Validation Based on Analytical Techniques of Metoclopramide Benzamide Derivative (Metoclopramide Base) and its determination from Solid Dispersion by Solvent Evaporation Method. J App Pharm Sci, 2018; 8(02): 018-026. 